\title{
On the turning modeling and simulation: 2D and 3D FEM approaches
}

\author{
M. Asad ${ }^{1, a}$, T. Mabrouki ${ }^{2}$, H. Ijaz ${ }^{1}$, M. Aurangzeb Khan ${ }^{1}$ And W. Saleem ${ }^{1}$ \\ 1 Department of Industrial \& Mechanical Engineering, School of Engineering, University of Management \& Technology, \\ 54770 Lahore, Pakistan \\ 2 Université de Lyon, CNRS, INSA-Lyon, LaMCoS, UMR 5259, 69621 Lyon, France
}

Received 11 May 2013, Accepted 26 May 2014

\begin{abstract}
For qualitative prediction of chip morphology and quantitative prediction of burr size, $2 \mathrm{D}$ and 3D finite element (FE) based turning models have been developed in this paper. Coupled temperaturedisplacement machining simulations exploiting the capabilities of Abaqus ${ }^{\circledR}$ with a particular industrial turning insert and a newly proposed geometrical version of this insert have been performed. Limitations of 2D models in defining the chip morphologies and surface topologies have been discussed. The phenomenological findings on the Poisson burr (Side burr) formation using 3D cutting models have been highlighted. Bespoke geometry of the turning insert has been found helpful in reducing the Poisson burr formation, as it reduces the contact pressures at the edges of tool rake face-workpiece interface. Lower contact pressures serve to decrease the material flow towards workpiece edges (out of plane deformation). In contrast, higher contact pressures at tool rake face-workpiece interface lead to more material flow towards workpiece edges resulting in longer burr. Simulation results of chip morphologies and cutting forces for turning an aluminum alloy A2024-T351 have been compared with the experimental ones. Finally, it has been concluded that the newly proposed geometry of the insert not only decreases the burr but also helpful in lessening the magnitude of tool-workpiece initial impact.
\end{abstract}

Key words: Orthogonal turning / FE model / Poisson burr formation / chip morphology / A2024-T351

\section{Introduction}

Researchers and production engineers are now well aware of the fact that better comprehension of the physics of the cutting phenomenon can be beneficial in increasing the machining efficiency. Latter, this can be achieved by suitable selection of cutting parameters, insert geometries, cutting conditions and machine tools, etc. [1,2]. The role of finite elements, numerical methods and techniques has been vital in this context.

Multiphysical nature of machining phenomenon, complex geometry of cutting tools and computational limits have restricted the researchers to limit their studies to 2D models (employing plane strain or plane stress hypotheses). The simplified 2D approaches have sufficiently served their intended purpose. However these are unable to model and predict some imperative informations of machining phenomena like burr formation process, oblique cutting forces, tool wear, drilling, etc. To overcome the

\footnotetext{
a Corresponding author: masadakhtar@yahoo.com
}

shortcomings of 2D models, valuable researches considering 3D models and techniques have been carried out in recent decade [3-7].

In this continuation to improve the comprehension of cutting and eventually to increase the machining efficiency, the study presents 2D and 3D FE based orthogonal turning models. Two by-products of machining process namely chip and burr which influence the economics of machining process in terms of surface quality and costly deburring process, respectively $[8,9]$ have been numerically investigated in the present work. Quantitative burr prediction has been realized by using nodes displacement method [10].

The study highlights the importance of contact pressures at the edges of tool rake face-workpiece interface in promoting the side burr (Poisson burr) formation and chip morphology. Orthogonal turning simulations with an industrial turning tool insert (Sandvik ${ }^{1}$ uncoated carbide

\footnotetext{
${ }^{1}$ Manufacture is not responsible for the results. The name is provided to apprise the readers.
} 


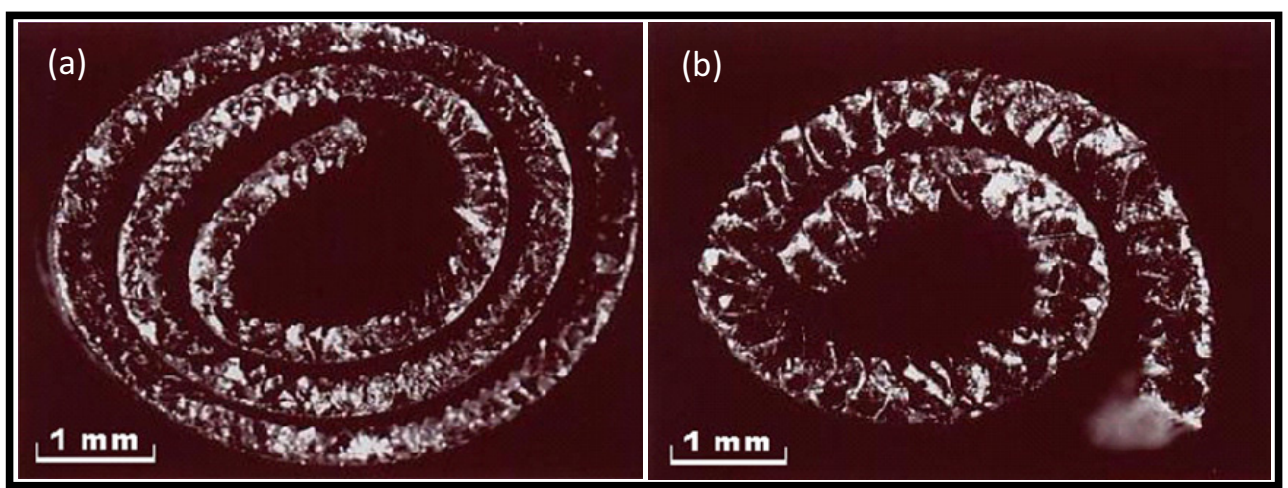

Fig. 1. Experimental chip for $V_{C}=800 \mathrm{~m} / \mathrm{min}, a_{P}=4 \mathrm{~mm}$. (a) Continuous chip for $f=0.3 \mathrm{~mm} / \mathrm{rev}$. (b) Segmented chip for $f=0.5 \mathrm{~mm} / \mathrm{rev}$.

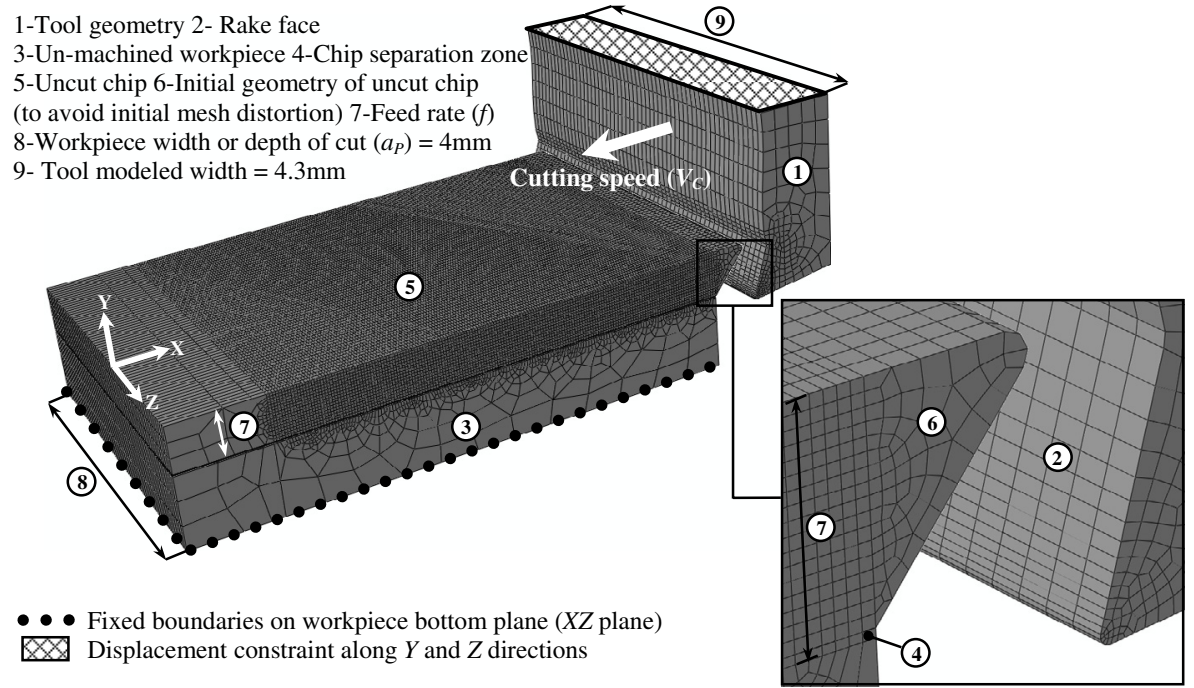

Fig. 2. Geometrical model conceived for 3D orthogonal turning operation.

insert: CCGX 1204 08-AL H10) and a bespoke version of this insert have been carried out. The effects of the geometries of the aforesaid inserts on chip morphology and side burr formation have been discussed.

\section{Turning experiments}

To realize orthogonal turning, tool insert's edge (insert with $0^{\circ}$ edge inclination angle and $90^{\circ}$ edge entering angle) was orthogonal to both feed and cutting speed. Cutting forces for machining parameters: feed rate $(f)=0.3$ and $0.5 \mathrm{~mm} / \mathrm{rev}$, depth of cut $\left(a_{P}\right)=4 \mathrm{~mm}$, cutting speed $\left(V_{C}\right)=800 \mathrm{~m} / \mathrm{min}$ were registered. Chips were recovered and polished (Fig. 1). Experimental approach is elaborately discussed in authors recent work (see Ref. [8]).

\section{FE-models for turning operation}

\subsection{Geometry, interactions and mesh}

To realize $2 \mathrm{D}$ and $3 \mathrm{D}$ FE modeling for turning process, explicit approach of a commercially available FE code
Abaqus ${ }^{\circledR}$ was exploited. Geometrical model was built in corroboration with experimental details (feed, depth of cut, insert profile, cutting angles, etc.) Figure 2, shows the conceived geometry for orthogonal machining.

FE-based simulation models employ either of the three main formulations: Lagrangian formulation, Eulerian formulation or Arbitrary Lagrangian-Eulerian formulation. Each formulation has its significance and limitation in dealing various natures of physical problems. Present work uses the Lagrangian formulation to simulate the turning operation. Literature concerning the Lagrangian based cutting simulation has witnessed severe mesh distortions at the tool-workpiece interface. To improve the latter phenomenon and interactions, workpiece was conceived in three individual parts namely: uncut chip, chip separation zone and un-machined workpiece. Onward, "tie-constraint algorithm" integrated in Abaqus ${ }^{\circledR}$ was employed to assemble these parts to produce a single entity "workpiece".

In the simulation, tool can displace only along $X$ direction. Whilst, the movement of workpiece was completely restricted by its bottom plane. For 3D coupled temperature-displacement simulation both tool and 
Table 1. Material properties [13].

\begin{tabular}{lcc}
\hline Physical parameters & Workpiece $(\mathrm{A} 2024$-T351) & Insert (tungsten carbide) \\
\hline Density, $\rho\left(\mathrm{Kg} / \mathrm{m}^{3}\right)$ & 2700 & 11900 \\
Young's Modulus, $E(\mathrm{MPa})$ & 73000 & 534000 \\
Poisson's ratio, $\nu$ & 0.33 & 0.22 \\
Fracture energy, $G_{f}(\mathrm{~N} / \mathrm{m})$ & $20 \mathrm{E} 3$ & $\mathrm{x}$ \\
Specific heat, $C_{p}\left(\mathrm{~J} \mathrm{~kg}{ }^{-1}{ }^{\circ} \mathrm{C}^{-1}\right)$ & $0.557 T+877.6$ & 400 \\
Expansion coefficient, $\alpha_{d}\left(\mu \mathrm{m} \mathrm{m}^{-1}{ }^{\circ} \mathrm{C}^{-1}\right)$ & $8.9 \times 10^{-3} T+22.2$ & $\mathrm{x}$ \\
Thermal conductivity, $\lambda$ & $25 \leqslant T \leqslant 300: \lambda=0.247 T+114.4$ & 50 \\
$\left(\mathrm{~W} \mathrm{~m}{ }^{-1} \mathrm{C}^{-1}\right)$ & $300 \leqslant T \leqslant T_{m}: \lambda=-0.125 T+226$ & $\mathrm{x}$ \\
Melting temperature, $T_{m}\left({ }^{\circ} \mathrm{C}\right)$ & 520 & 25 \\
Room temperature, $T_{r}\left({ }^{\circ} \mathrm{C}\right)$ & 25 & \\
\hline
\end{tabular}

workpiece were meshed with thermally coupled continuum brick elements C3D8RT. Whereas, thermally coupled quadrilateral continuum elements CPE4RT (with plane strain formulation) were used for $2 \mathrm{D}$ case. To reduce the CPU time variable mesh densities have been created at various sections of workpiece and tool. For "uncut chip" and "chip separation" zones a mesh size of $30 \mu \mathrm{m}$ was adopted. Whereas, higher mesh densities (mesh size $\approx 30 \mu \mathrm{m}$ ) were generated only at those specific sections of "tool" and "un-machined workpiece" which were prone to come in contact during cutting simulations. This scheme has resulted in 181132 elements (3D model) and it took approximately eight hours to complete the simulation (32 Bit, core i5, 3.2 GHz, 4 GB RAM System). For onward comparison of simulation results $2 \mathrm{D}$ model geometry, boundary conditions and mesh sizes were similar to $3 \mathrm{D}$ one.

To model the frictional contact between tool workpiece, Zorev's stick-slip contact friction model [11] with an average friction coefficient $\mu=0.17$ [12] has been assumed in the present work.

\subsection{Material constitutive modeling}

Material model based on the coupling between damage and fracture energy was used to realize the chip formation and separation processes. Model is explicitly summarized in authors previous work [8]. Nevertheless, some necessary formulae are reproduced here. To calculate equivalent stresses, Johnson and Cook (Eq. (1)) model has been used. Material damage formulations have been defined in two steps: damage initiation (JC shear failure model (Eq. (2)), and damage evolution.

$$
\begin{aligned}
\bar{\sigma}_{J C}= & \left(A+B \bar{\varepsilon}^{n}\right)\left[1+C \ln \left[\frac{\dot{\bar{\varepsilon}}}{\dot{\dot{\bar{\varepsilon}}_{0}}}\right]\right]\left[1-\left[\frac{T-T_{r}}{T_{m}-T_{r}}\right]^{m}\right] \\
\bar{\varepsilon}_{0 i}= & {\left[D_{1}+D_{2} \exp \left[D_{3} \frac{P}{\bar{\sigma}}\right]\right]\left[1+D_{4} \ln \left[\frac{\dot{\bar{\varepsilon}}}{\dot{\bar{\varepsilon}}_{0}}\right]\right] } \\
& \times\left[1+D_{5}\left[\frac{T-T_{r}}{T_{m}-T_{r}}\right]\right]
\end{aligned}
$$

where, $A$ is the initial yield stress, $B$ is the hardening modulus, $C$ is the strain rate dependency coefficient, $m$ is the thermal softening coefficient, $n$ is the work-hardening exponent, $T$ is the temperature at a given calculation instant, $T_{r}$ is the room temperature, $T_{m}$ is the melting temperature, $\bar{\varepsilon}$ is the equivalent plastic strain, $\dot{\bar{\varepsilon}}$ is the plastic strain rate and $\dot{\bar{\varepsilon}}_{0}$ is the reference strain rate. $D_{1}$ to $D_{5}$ are the coefficients of $J C$ material shear failure initiation criterion, $p$ is the hydrostatic pressure, $\bar{\sigma}$ is the von Mises equivalent stress and $p / \bar{\sigma}$ is the stress triaxiality. Damage is assumed to be initiated in an element when scalar damage parameter $\omega_{0 i}$ (Eq. (3)) exceeds one.

$$
\omega_{0 i}=\sum \frac{\Delta \bar{\varepsilon}}{\bar{\varepsilon}_{0 i}}
$$

whereas, a scalar stiffness degradation parameter $D$ is used to define damage evolution. Later, it evolves linearly (Eq. (4), used for chip separation zone part of the workpiece) or exponentially (Eq. (5), used for uncut chip part of the workpiece).

$$
\begin{aligned}
& D=\frac{L \bar{\varepsilon}}{\bar{u}_{f}}=\frac{\bar{u}}{\bar{u}_{f}} \\
& D=1-\exp \left(-\int_{0}^{\bar{u}} \frac{\bar{\sigma}}{G_{f}} d \bar{u}\right)
\end{aligned}
$$

where, $\Delta \bar{\varepsilon}$ is the equivalent plastic strain increment and $\bar{\varepsilon}_{0 i}$ the plastic strain at damage initiation. $L$ is the characteristic length assumed to the cubic root of the integration point element volume. $G_{f}$ is the fracture energy dissipation (required to open unit area of crack and is defined as a material parameter), $\bar{u}$ is the equivalent plastic displacement and $\bar{u}_{f}$ is the equivalent plastic displacement at failure expressed by following relation. Equation (6), defines the equivalent plastic displacement at failure $\bar{u}_{f}$.

$$
\bar{u}_{f}=\frac{2 G_{f}}{\sigma_{y}}
$$

During cutting simulation elements loss their stiffness and load carrying capacity as the value of scalar stiffness degradation parameter $D$ approaches to one. These element(s) can be deleted (element(s) from chip separation zone of workpiece) from rest of the mesh, allowing chip separation. Thermo-mechanical properties of cutting insert (tungsten carbide) and workpiece material (A2024T351) are specified in Table 1 and material constitutive model properties are defined in Table 2, respectively [13]. 
Table 2. Constitutive model parameters for A2024-T351 [13].

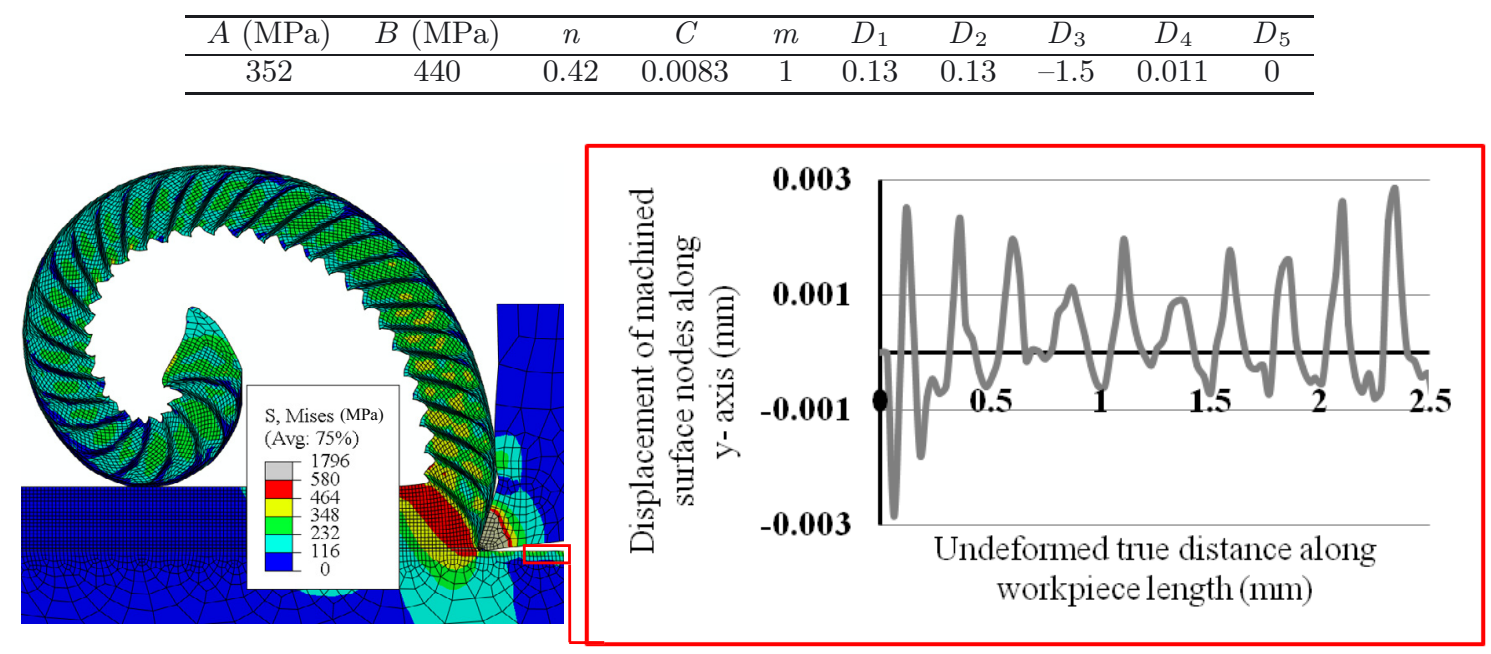

Fig. 3. 2D numerical chip morphology and surface topology for $V_{C}=800 \mathrm{~m} / \mathrm{min}, f=0.5 \mathrm{~mm} / \mathrm{rev}$.

Table 3. Comparison of experimental and numerical cutting forces $\left(F_{C}\right)$ for $V_{C}=800 \mathrm{~m} / \mathrm{min}, a_{P}=4 \mathrm{~mm}$ with various feed rates.

\begin{tabular}{ccc}
\hline \multirow{2}{*}{ Cutting approach } & \multicolumn{2}{c}{ Feed rate $f(\mathrm{~mm} / \mathrm{rev})$} \\
\cline { 2 - 3 } & $\begin{array}{c}0.3 \\
(\mathrm{~mm} / \mathrm{rev})\end{array}$ & $\begin{array}{c}0.5 \\
(\mathrm{~mm} / \mathrm{rev})\end{array}$ \\
\hline Experiment & 738 & 1110 \\
2D FE simulation & 697 & 1100 \\
3D FE simulation & 686 & 1090 \\
\hline
\end{tabular}

\section{Results and discussions}

To improve the comprehension of the cutting phenomenon the results of the orthogonal turning simulations have been discussed in the present section. 2D and $3 \mathrm{D}$ numerical simulations for $V_{C}=800 \mathrm{~m} / \mathrm{min}, f=0.3$ and $0.5 \mathrm{~mm} / \mathrm{rev}, a_{P}=4 \mathrm{~mm}$ with an industrial turning tool insert geometry have been performed. Experimental match of chip morphologies and cutting forces have been shown. Onward, simulation results with a modified version of the geometry of the turning tool insert have been presented.

\subsection{Numerical simulations with industrial turning tool insert geometry (2D case)}

A reasonable comparison of $2 \mathrm{D}$ simulated chip morphology (Fig. 3) with the experimental chip (Fig. 1b) for $V_{C}=800 \mathrm{~m} / \mathrm{min}, f=0.5 \mathrm{~mm} / \mathrm{rev}$ can be figured out. Cutting forces $\left(F_{C}\right)$ are in a good match with the experimentation data (Tab. 3). Cutting performed with these parameters have generated a segmented chip with ondulated surface profile as indicated by machined surface nodes displacement.

Although, informative results could be deduced by 2D simulation. However, results are not valid for whole model but are limited to provide the information only for a plane section with unit thickness. Comparison of $2 \mathrm{D}$ and $3 \mathrm{D}$ numerical chips (discussed in next section) have shown that $2 \mathrm{D}$ models predict the chip morphology and related information on a section which passes through middle of the workpiece cutting depth $a_{P}$. Latter, this limits the 2D models in predicting the results of vast industrial interest, like burr, which produces at edges of machined workpiece.

\subsection{Numerical simulations with industrial turning tool insert geometry (3D case)}

Figure 4, shows 3D simulated chip morphology for cutting speed $V_{C}=800 \mathrm{~m} / \mathrm{min}, f=0.5 \mathrm{~mm} / \mathrm{rev}$, $a_{P}=4 \mathrm{~mm}$. Numerical chip (Fig. 4a) is globally comparable with the experimental one (Fig. 1b). Numerically obtained cutting forces were also found in good corroboration with the experimentally registered values (Tab. 3). Insight observation of the 3D chip (Fig. 4a) shows that during cutting, though the material flow is mainly along $X$ and $Y$ directions and chip has been evolved in $X Y$-plane. However, material flow along $Z$ direction towards workpiece edges (out of plane deformation) cannot be completely wiped out. This result is in close corroboration with the recent findings of Qu et al. [5] and Zhang et al. [14] on side burr formation mechanisms.

Furthermore, material flow along $Z$ direction (towards workpiece edges) has generated non identical chip morphologies at various sections (at section $Z= \pm 2$ and $Z=0$ ) and subsequently non identical machined surface topologies can be figured out on these sections of the workpiece (Fig. 5).

The percentage volume of the material that flows towards workpiece edges along $Z$ direction is negligible in comparison with the volume that flows along $X$ and $Y$ directions. However, its effect in changing frictional contact conditions is considerable. Since, it has increased the contact pressure on edges of the tool insert-workpiece interface (Fig. 6). 


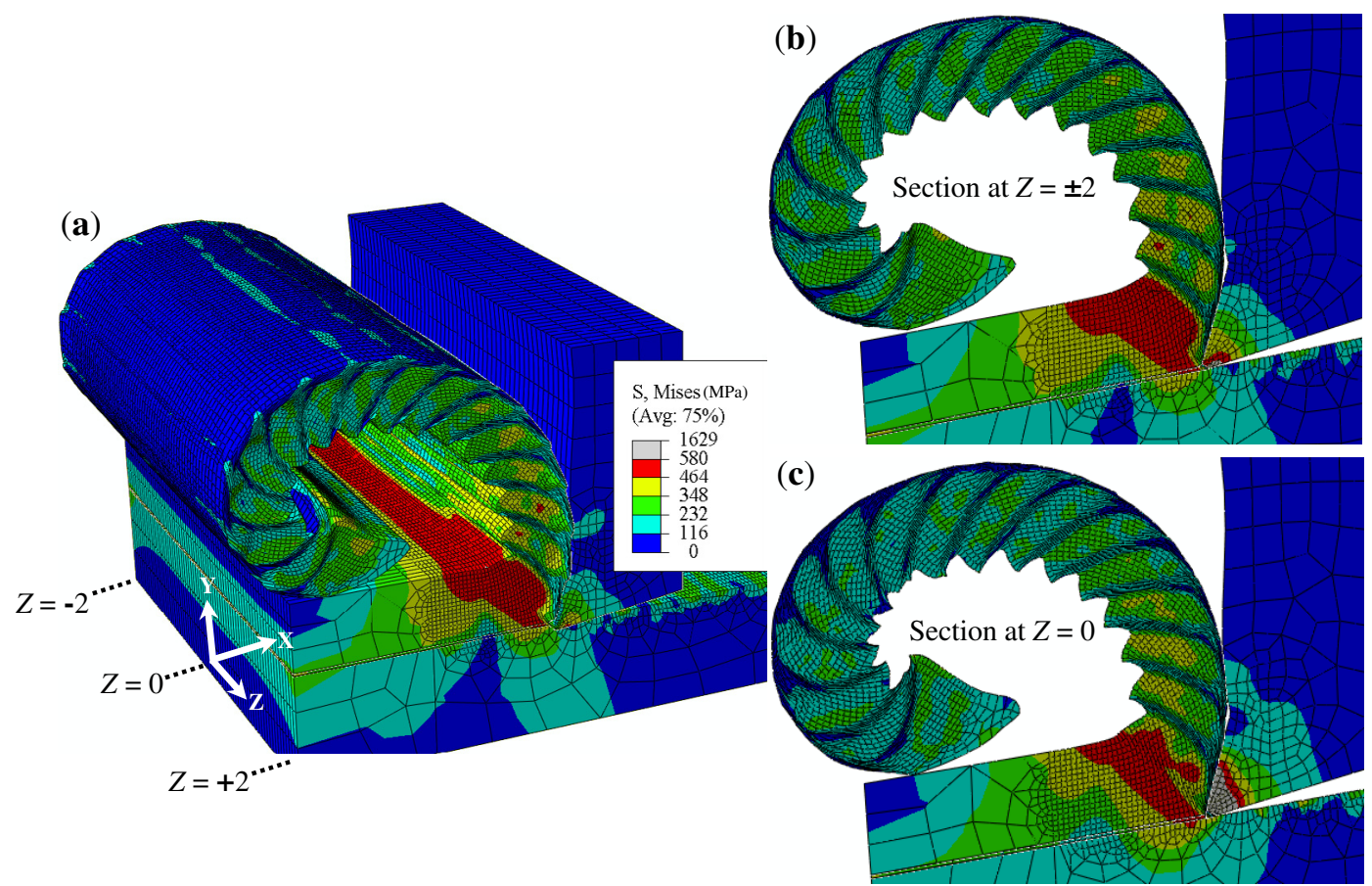

Fig. 4. Numerical chip morphology for $V_{C}=800 \mathrm{~m} / \mathrm{min}, f=0.5 \mathrm{~mm} / \mathrm{rev}, a_{P}=4 \mathrm{~mm}$. (a) $3 \mathrm{D}$ segmented chip evolution. (b) Tool-chip section in $X Y$-plane at $Z= \pm 2$. (c) Tool-chip section in $X Y$-plane at $Z=0$.

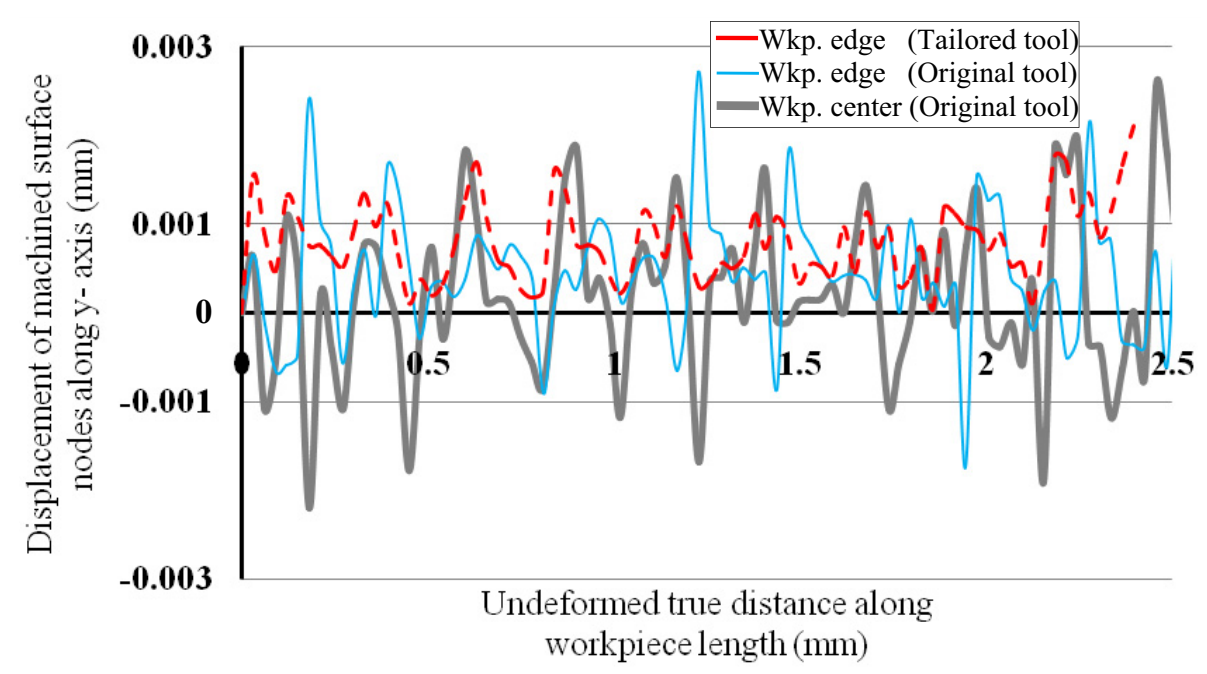

Fig. 5. Surface topology at various sections (workpiece edge or workpiece center) along cutting depth, for $V_{C}=800 \mathrm{~m} / \mathrm{min}$, $f=0.5 \mathrm{~mm} / \mathrm{rev}, a_{P}=4 \mathrm{~mm}$.

This enhances the side burr (Poisson burr) formation, as can be seen by displacements of machined surface nodes (at workpiece edges) along $Z$-axis (Fig. 7).

In Figure 7, where zero value along ordinate represents un-machined workpiece edge (at $Z=+2$ ), it can be seen that under the combined effects of out of plane deformation and increased frictional interaction, machined surface nodes(at edges) have been displaced upto $2 \mu \mathrm{m}$ (quantitative prediction of Poisson burr). Choi et al. [10] have also employed node displacement scheme to predict burr formation during drilling process.

\subsection{Numerical simulations with bespoke turning tool insert geometry (3D Case)}

In previous section it has been found that both out of plane deformation and increased frictional interaction enhance side or Poisson burr formation. In the current section with an ultimate aim to reduce burr formation, a modified version of the original insert with minimum possible changes in original geometry (Fig. 8a) and no change in cutting angles has been suggested, as shown in Figure 8b. 


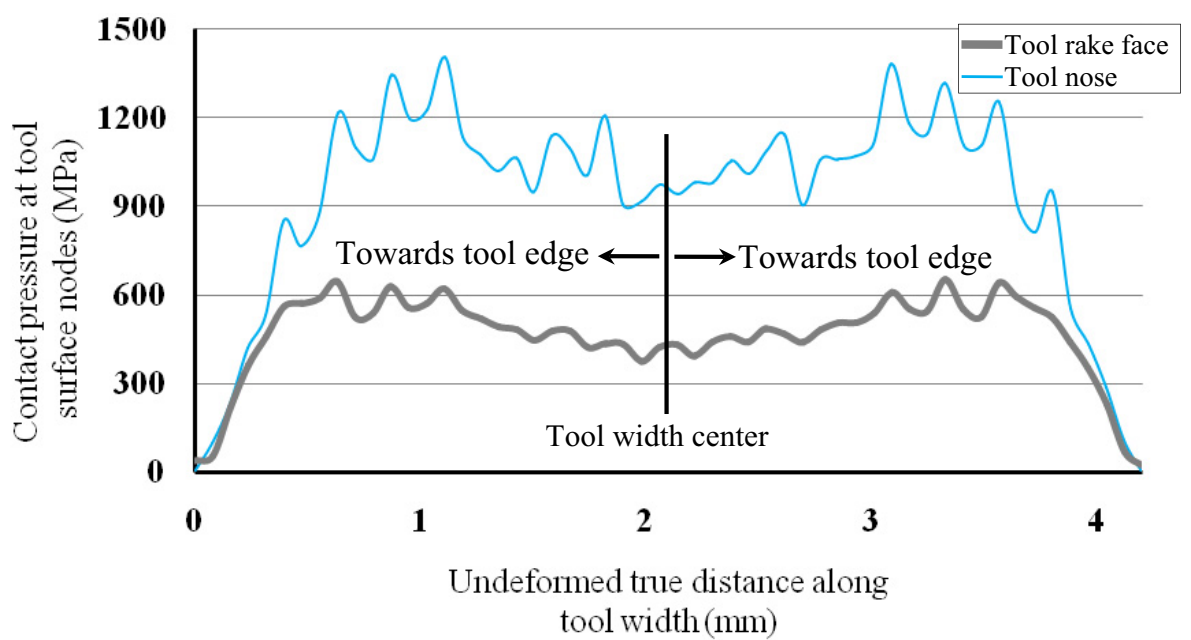

Fig. 6. Contact pressure (MPa) evolution at tool cutting face along tool width $\left(Z\right.$-axis) for $V_{C}=800 \mathrm{~m} / \mathrm{min}, f=0.5 \mathrm{~mm} / \mathrm{rev}$, $a_{P}=4 \mathrm{~mm}$.

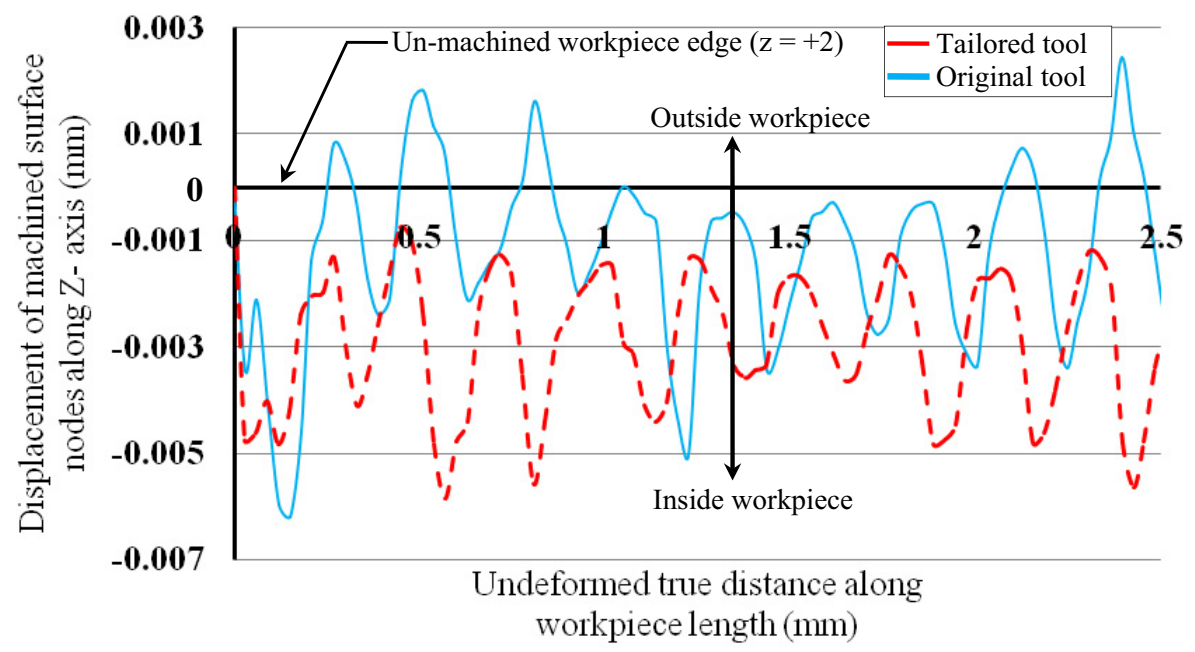

Fig. 7. Machined surface nodes displacement (at workpiece edge, $Z=+2$ ) for two cutting tool configurations, for $V_{C}=$ $800 \mathrm{~m} / \mathrm{min}, f=0.5 \mathrm{~mm} / \mathrm{rev}, a_{P}=4 \mathrm{~mm}$.

Geometry of the proposed convex shaped insert helps to decrease frictional contact at insert-workpiece interface. The cutting simulations reproduced with this insert have shown a considerable decrease in the side burr formation in terms of machined workpiece nodes displacements at edges, as can be figured out in Figure 5 (nodes displacements along $Y$-axis) and Figure 7 (nodes displacements along $Z$-axis). Furthermore, only a small volume of the workpiece comes in contact with insert (bespoke insert) in the beginning of cutting operation. This helps to reduce the amplitude of the cutting force peak at initial impact of the tool with workpiece material (Fig. 9). High energy initial contact reduces insert life, as well as cause severe mesh distortions during cutting simulations.

Moreover, in Figure 10a it can be seen that the continuous chip morphology (at cutting time $t=0.25 \mathrm{~ms}$ for $V_{C}=800 \mathrm{~m} / \mathrm{min}, f=0.3 \mathrm{~mm} / \mathrm{rev}, a_{P}=4 \mathrm{~mm}$ ) which is comparable with experimental one (Fig. 1a) has made self contact with the workpiece. Latter contact helps to fragment the chip [8]. However, the chip produced (Fig. 10b) with newly proposed insert which is globally comparable with the chip produced with original insert (Fig. 10a) and the experimental one, is far away to make self contact. This suggests likely production of long fragment chips with the proposed insert configuration.

\section{Conclusions}

To improve the comprehension of mutilphysical phenomenon of cutting process $\mathrm{FE}$ based 2D/3D turning models have been developed. Computational results show that during cutting process a small percentage of material volume flows towards workpiece edges (out of plane deformation). This changes the frictional contact conditions at the edges of cutting tool insert-workpiece interface, as indicated by the increased contact pressure. Simultaneous effects of out of plane deformation and increased frictional interaction on edges displace machined workpiece 


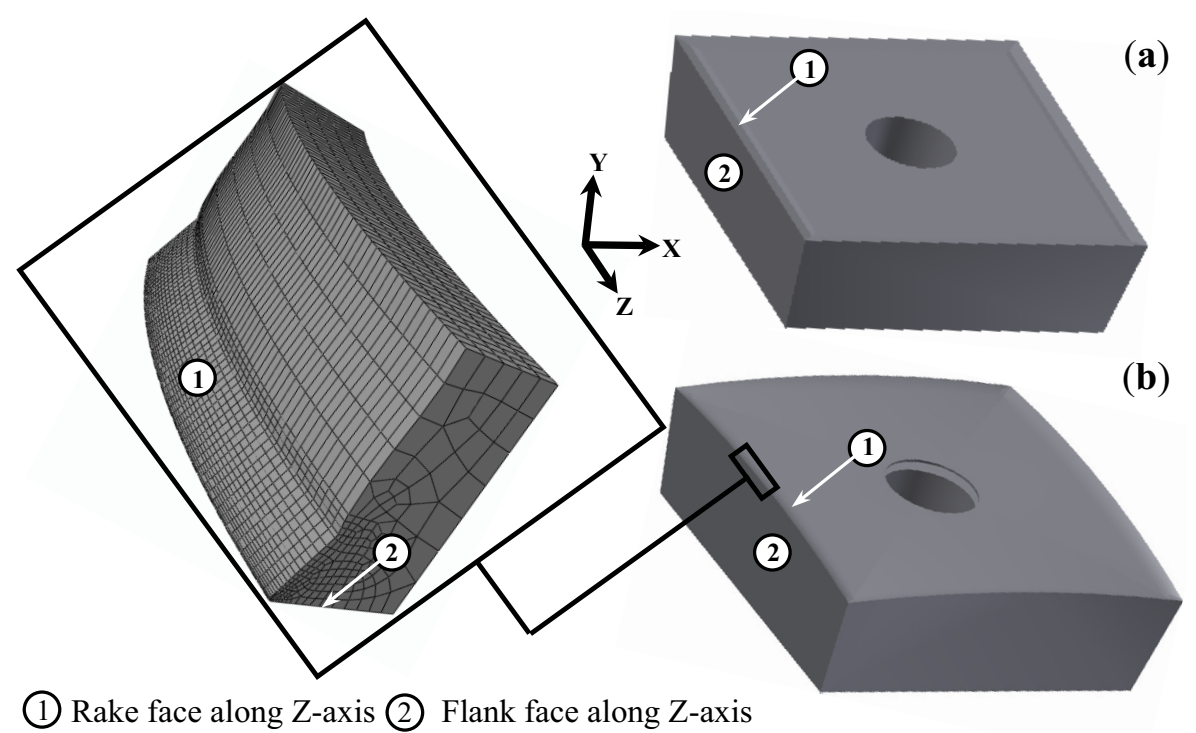

Fig. 8. Turning insert used for simulations. (a) Original geometry. (b) Modified convex shaped geometry.

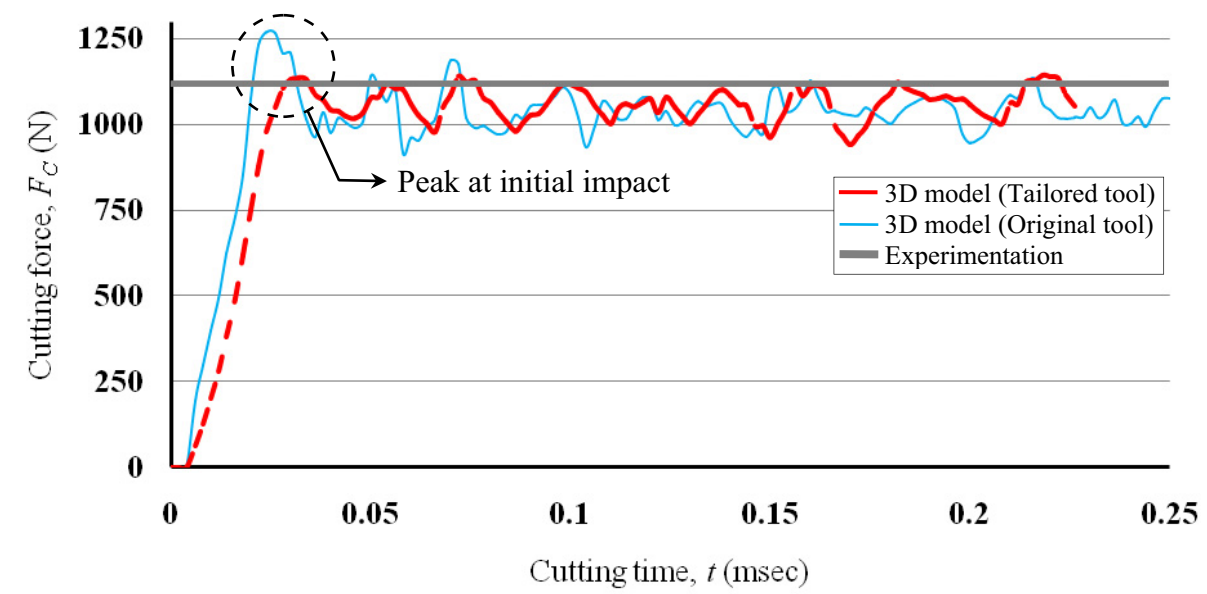

Fig. 9. Cutting force plots with various cutting approaches for $V_{C}=800 \mathrm{~m} / \mathrm{min}, f=0.5 \mathrm{~mm} / \mathrm{rev}, a_{P}=4 \mathrm{~mm}$.
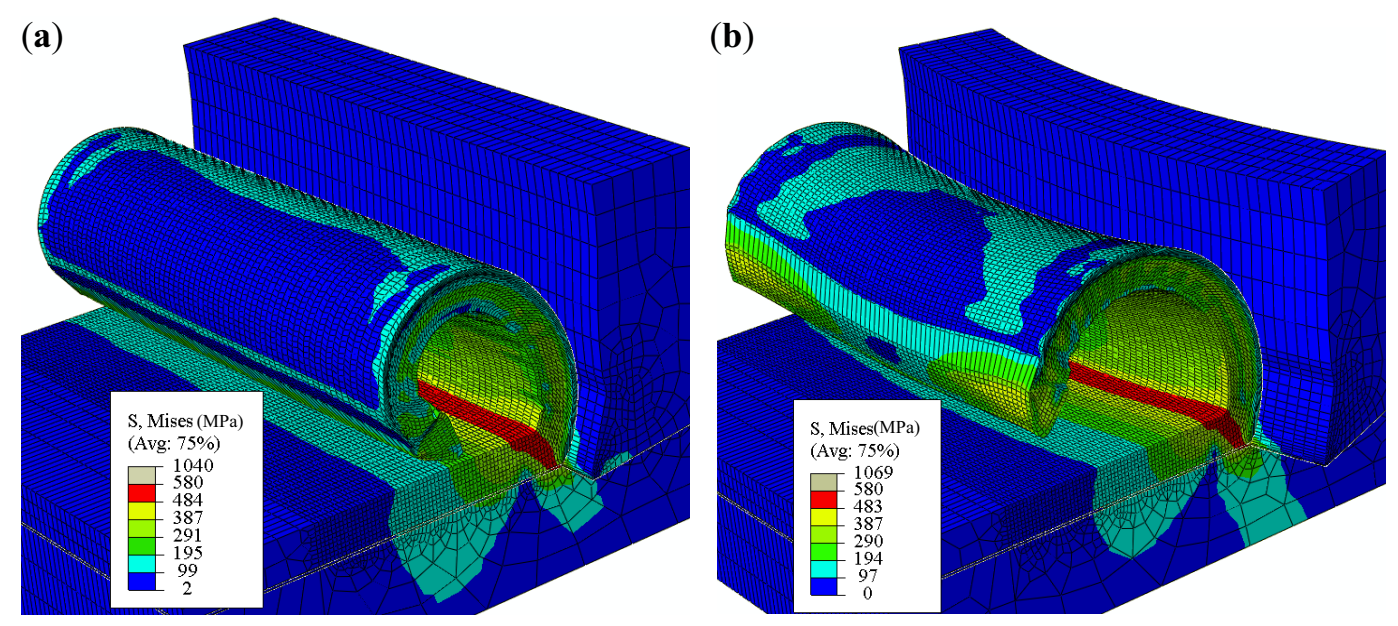

Fig. 10. 3D numerical chip morphology at cutting time $t=0.25 \mathrm{~ms}$ for $V_{C}=800 \mathrm{~m} / \mathrm{min}, f=0.3 \mathrm{~mm} / \mathrm{rev}, a_{P}=4 \mathrm{~mm}$ with (a) original tool, (b) modified convex shaped tool. 
nodes along $Y$ and $Z$ directions (side burr prediction). It was found that $2 \mathrm{D}$ models are unable to characterize some unique machining phenomena like burr formation, oblique cutting, drilling, etc.

Bespoke version of a particular turning insert has been proposed. The convex shaped geometry of the proposed insert is quite helpful in reducing the frictional contact at the edges of the tool insert-workpiece interface and eventually reduction in side or Poisson burr formation. Latter, this has been verified by reproducing the numerical simulations with this insert. The insert was also found useful in reducing the high energy initial impact of the insert with the workpiece material. However, due to reduced insert-workpiece frictional interaction, the proposed insert is susceptible to produce long fragment chips.

\section{References}

[1] M. Asad, T. Mabrouki, J.F. Rigal, Finite-element-based hybrid dynamic cutting model for aluminium alloy milling, Proc. IMechE Part b: J. Engng. Mf. 224 (2010) $1-13$

[2] F. Salvatore, T. Mabrouki, H. Hamdi, The use of numerical simulations to improve a new analytical chip formation model, Mechanics \& Industry 13 (2012) 405-414

[3] A. Attanasio, E. Ceretti, S. Rizzuti, D. Umbrello, F. Micari, 3D finite element analysis of tool wear in machining, Ann. CIRP Mf. Tech. 57 (2008) 61-64

[4] M.J. Chen, H.B. Ni, Z.J. Wang, Y. Jiang, Research on the modeling of burr formation process in micro-ball end milling operation on Ti-6Al-4V, Int. J. Adv. Manuf. Technol. 62 (2012) 901-912
[5] H.J. Qu, J.H. Yang, G.C. Wang, Simulation and control of two side direction burr, App. Mech. Mater. (2012) DOI: 10.4028/www.scientific.net/AMM.143-144.428

[6] W.J. Deng, W. Xia, Y. Tang, Finite element simulation for burr formation near the exit of orthogonal cutting, Int. J. Adv. Manuf. Technol. 43 (2009) 1035-1045

[7] M. Asad, T. Mabrouki, A.A. Memon, S.M.A. Shah, M.A. Khan, Three-dimensional finite element modeling of rough to finish down-cut milling of an aluminum alloy, Proc. IMechE Part b: J. Engng. Mf. 227 (2013) 75-83

[8] T. Mabrouki, F. Girardin, M. Asad, J.F. Rigal, Numerical and experimental study of dry cutting for an aeronautic aluminium alloy (A2024-T351), Int. J. Mach. Tools Mf. 48 (2008) 1187-1197

[9] S. Ko, D.A. Dornfeld, A study on burr formation mechanism, J. Eng. Mater. Technol. 113 (1991) 75-87

[10] J. Choi, S. Min, D.A. Dornfeld, Finite element modeling of burr formation in drilling of a multi-layered material, Consortium on Deburring and Edge Finishing in UC Berkeley, USA (2004)

[11] N.N. Zorev, Interrelationship between shear processes occurring along tool face and on shear plane in metal cutting, International Research in Production Engineering Conference ASME, 1963, pp. 42-49

[12] W. Ni, Y.T. Cheng, A.M. Weiner, T.A. Perry, Tribological behaviour of diamond-like carbon (DLC) coatings against aluminium alloys at elevated temperatures, Surf. Coat. Technol. 201 (2006) 3229-3234

[13] M. Asad, Elaboration of concepts and methodologies to study peripheral down-cut milling process from macroto-micro scales, Dissertation. INSA Lyon. France, 2010

[14] T. Zhang, L. Zhanqiang, X. Chonghai, Influence of size effect on burr formation in micro cutting, Int. J. Adv. Manuf. Technol. (2013) DOI: 10.1007/s00170-013-4801-8 